\section{University of New Hampshire}

Carsey School of Public Policy
CARSEY RESEARCH

National Issue Brief \#140

\title{
Social Service Delivery in Two Rural Counties
}

\author{
Jessica A. Carson \& Marybeth J. Mattingly
}

$\mathrm{W}$ hen low-income residents struggle to make ends meet, non-profit social service agencies can help fill the gaps. In doing so, these agencies must find sufficient funding, retain qualified staff, and craft efficient service delivery mechanisms that are respectful of clients and communities. Some of the challenges that service providers encounter are exacerbated by rural characteristics, such as vast geographic distances and the lack of economies of scale. Yet in some ways rurality is beneficial, as small communities can facilitate community engagement and providers can engage natural supports in their service delivery work.

The ways that rural providers meet clients' needs vary with the specific characteristics of the community. ${ }^{1}$ As a result, the delivery of services may be more effective in some communities than in others. In this brief, we use interview and focus group data to explore how the characteristics of two rural New England counties influence the types of services available to residents and the ways those services are delivered.

Nonprofit service agencies nationwide encounter challenges in maintaining adequate funding, and organizations in rural places face particular difficulty.

\section{Rural Residents Need Supportive Services, but Services Are Often Underfunded}

In Clay and Union Counties, as in rural places nationwide, the predominance of low-wage work means workers need income support. But seasonal jobs and fluctuating work hours, alongside challenges with transportation and child care, mean that rural workers, including many in the two communities studied,

\section{KEY FINDINGS}

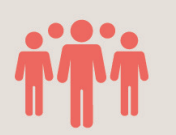

Challenges of funding and geographic distance along with disparate needs among community members, shape the ways that rural social service providers support their clients.

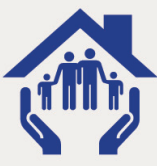

Community characteristics, like a place's history, population composition, income inequality, and degree of remoteness, influence how efficiently social service agencies work.

fall short in meeting the work requirements of some federal safety net programs. ${ }^{2}$ As such, communitybased services outside of the formal safety net are especially important.

Nonprofit service agencies nationwide encounter challenges in maintaining adequate funding, and organizations in rural places face particular difficulty. Long distances and high transportation costs, coupled with the absence of economies of scale, make it difficult to stretch limited per capita dollars. Lack of density makes obtaining grant funds a struggle, despite high need. One Union County educator explained, "I think the needs assessment and how they do it at least has to be looked at....People want to see the [large] numbers [of people served], they want to see the [numeric] results [of their investment] and... what they need to assess [is] the need. Well, you're gonna get the numbers in the populated areas, okay, but the need is much more in the rural areas."

Funding challenges are salient in different ways in each county. Union County struggles to compete against other rural communities for grant funds given its very low population density; despite having a large share of its population in poverty, delivering services to few people, especially in places where service providers have long commutes between 


\section{Box 1. About the Study on Community and Opportunity Series}

What is it like to live through the challenges confronted by vulnerable families? In our new Study on Community and Opportunity, we use data from five years of interviews and focus groups with residents, social service providers, and community members (eighty-five participants in all) from two rural New England communities to examine in depth the issues that affect vulnerable families and to document the everyday hurdles rural residents face as they try to make ends meet.

The study covers a wide range of topics pertaining to these challenges in two different kinds of rural places. We call one community Union County, where a remote location and a seasonal, natural resource-based economy have generated a history of poverty, and the other, Clay County, where a vibrant mix of natural amenities and a relatively central location attract wealthy retirees and tourists from within and outside the state. Talking with people in these communities, we learned about their efforts to find and keep work, the use and adequacy of the social safety net, and some of the challenges and advantages of living in a rural community.

Our first brief in this series describes some of the ways that restricted rural housing stock affects working families. In this brief, we report on how geographic and cultural characteristics shape social service delivery options in these two different rural communities, and examine the ways that providers structure programs to adapt to the respective challenges, opportunities, and resources.

clients, tends to be seen as an inefficient investment. In Clay County, on the other hand, statistically documenting economic need is made difficult by the pockets of wealthier retirees in the region's waterfront areas. These high incomes skew Clay's overall poverty rates downward, which means that Clay often doesn't appear-on paper-like a population in need. In addition, Clay's funding challenges are exacerbated by the diffuse nature of its service delivery network. As one provider explained, "There's something like 60-some nonprofits in Northern Clay County alone.... There's a lot of people reaching for the same dollar." 3

Union and Clay providers cited their frustration with specific funding-related programmatic shortages, including long wait lists for Section 8 housing and insufficient funding for fuel assistance.

Union and Clay providers cited their frustration with specific funding-related programmatic shortages, including long wait lists for Section 8 housing and insufficient funding for fuel assistance. "We were forced to shrink our area of coverage, but we still went through the money just as fast, because people just didn't get as much from [the federal heating assistance program] and the price had gone up so much," explained one Union provider. Beyond the lack of funds, providers and residents in both counties expressed frustration with their lack of flexibility in applying the funds they have. One Union educator highlighted the challenge in meeting "the quick needs that they have. The 'oh, my car just broke down and I need two hundred dollars to get this part to get it up and running again' or 'I'm out of gas, I don't know how I'm gonna get [where I need to go] tomorrow."'

In other cases, providers' frustrations centered not on the safety net's inability to meet needs in an emergency, but on being able to muster enough resources to help residents foster economic mobility. One Union provider explained, "I wish there was a way to help people get ahead... without having to lose out. Because I think a lot of times people, if they work, if they were to get a job and work, it's not going to pay enough and they're going to lose everything. They're going to lose their [state health insurance]. They're going to lose, whatever....They're going to go backwards. And I think that's too bad. I think it turns a lot of people from moving forward." 


\section{Agencies Can Work Together to Deliver Services, but Community Characteristics Matter}

One of the starkest contrasts between Union and Clay Counties is the difference in the extent of collaboration among service providers. In Union County, many providers recognized collaboration as a strength of the community, saying that it served the practical purposes of maximizing limited resources by eliminating duplication. This goal is further supported by the existence of a countywide collaborative body that facilitates cooperation between nonprofit agencies with the common goal of breaking down barriers for low-income people. The collaborative, by recognizing the overlapping challenges facing clients and the ways these issues intersect with different agencies' missions, serves as a physical and cultural hub for exchanging ideas and resources. One Union provider explained, "I've been doing this work for about 20 years, and I think when I first started, providers were competing against each other. There was plenty of money...so you needed people to put in your programs. And we've come full circle, which makes sense. We don't have the resources that we used to have, so now we're maximizing resources and we're leaning on each other, and we're all sitting at the same table talking about what [we can] do to make things better."

"We don't have the resources that we used to have, so now we're maximizing resources and we're leaning on each other, and we're all sitting at the same table talking about what [we can] do to make things better."

In contrast, providers in Clay County face challenges in cultivating interagency collaboration. One provider, new to the region, linked this to features of Clay's geography. "One of the things I'm learning is that [in] Clay County, because it doesn't have a community center, services tend to be kind of fragmented." Partially as a result of not having a physical center, there are fewer structured opportunities for communication and information exchange between providers, and thus very locally focused service organizations tend to work in relative isolation, often duplicating services that might otherwise be delivered more efficiently. This manifests as a persistent issue in Clay, where new nonprofit agencies emerge to serve the needs of a specific town or group of towns, even as there are already existing organizations with a similar mission in the service area. The Clay provider quoted above highlighted the implications of this duplication, saying: "It's not that people aren't cordial; it's not that people are back biting. But they're just maybe protective of their turf....I can't for the life of me figure out why providers would allow that to happen, [allow] themselves to be fragmented in advocating for...resources." Because of this very local focus, the service delivery system is characterized by a host of well-meaning but less efficient organizations. As in Union, Clay providers have attempted to organize into a collaborative, but the efforts there have been undermined by embedded community loyalties and divisions and the long-standing fractured organizational structure of the region's service network.

\section{Clay's Income Inequality Blurs Its Service Delivery Network's Purpose}

Clay's service organizations are diffuse and varied, and so are its residents. Income inequality is especially high in Clay, driven by the gaps between wealthy waterfront property owners, including retirees, and those in the rest of the county. Data from the Economic Policy Institute show that Clay County has higher income inequality than 99 percent of all U.S. counties; in contrast, Union County falls near the middle of the distribution. ${ }^{4}$ These income disparities, some driven by in-migration in Clay, have concrete implications for the service delivery systems. First, some Clay providers noted that retirees volunteer for service organizations that support causes like art and the environment and are not as invested in the same service and spending priorities that natives and locals are. One Clay provider explained, "Some of our volunteers are very wealthy and they're the ones that want to work at the hospital or the Chamber of Commerce, but they don't want to get down and dirty." Another Clay provider who worked with seniors explained, "Everybody you know [is] either going to need their lawn mowed or be the lawn mowers....There is really no middle class anymore here." This tension between differing priorities puts further pressure on the fractured nature of the service delivery network: Clay's service organizations tend to not only be locally focused, but also focused on single issues, like transportation or health. 


\section{Conclusion}

Poor residents struggle in both Clay and Union Counties, even though the two rural areas are quite different. In Clay, a steady stream of in-migrating retirees and vacationers produces a service-sector economy in which workers must patch together multiple jobs to afford rent in a housing market oriented toward preserving scenery and accommodating high-income newcomers. In Union, residents face a long-running history of a natural resource and seasonally based economy that has only contracted as young people move away to seek education and stability elsewhere. In both places, federal, state, and local safety nets help residents scrape by and achieve mobility over the long run.

Although state and federal programs like Medicaid, Social Security, the Supplemental Nutrition Assistance Program, Temporary Assistance for Needy Families, and the Earned Income Tax Credit are vital, residents must overcome enrollment challenges such as stigma around participation and inconsistent eligibility due to fluctuating employment.

But although state and federal programs like Medicaid, Social Security, the Supplemental Nutrition Assistance Program, Temporary Assistance for Needy Families, and the Earned Income Tax Credit are vital, residents must overcome enrollment challenges such as stigma around participation and inconsistent eligibility due to fluctuating employment. Local social services play important roles in bridging residual gaps, and in both places, providers stress the importance of programs that are developed and delivered by local community members to best address local needs. Efficiency varies, though, by level of collaboration.

Clay and Union providers, hampered by limited funds, bureaucracy, and large catchment areas, struggle to deliver all the services from which residents could benefit. Low-income Clay and Union residents face structural barriers to stability and mobility that are not necessarily distinct to those places, including uncertain economic opportunities and limited work supports like child care and transportation. Still, providers in Union
County seemed to have accepted these structural challenges head on, have designed a set of grassroots services that came from within the community, and have sought to propel residents forward. They have developed a strong, collaborative network that avoids duplication and generally successfully maximizes collective resources and efficiencies. While some in Clay County have sought similar collaboration, social differences among residents and along town borders, fragmented political and cultural concerns, and territorial boundaries have made it more difficult. As such, efforts to coordinate services and reduce duplication have been difficult to create and sustain. The extent to which they can become successful may depend on innovation and planning among key figures in the region's diverse organizations.

\section{Data and Methods}

This brief is adapted from a related journal article (Jessica A. Carson and Marybeth J. Mattingly, "We're All Sitting at the Same Table': Challenges and Strengths in Service Delivery in Two Rural New England Counties," Social Service Review 92, no. 3 (2018): 40131). The data come from the qualitative Carsey Study on Community and Opportunity, conducted between 2011 and 2015 via three focus groups in what we call Union County, two focus groups in what we call Clay County, and twenty-nine interviews in each place, for a total of eighty-five participants. Data were transcribed and analyzed for emergent themes in NVivo 10. For full details on the study's recruitment and analysis strategies, see the journal article. To protect the privacy of people in these small communities, we withhold details about people's specific professions and personal lives in this brief. All the themes discussed emerged from our analyses of these data; however, the qualitative data are supplemented in this brief with data from the U.S. Census Bureau's American Community Survey (2016 five-year estimates), the 2000 and 2010 Decennial Censuses, 2016 Population Estimates, and the 2015 County Business Patterns to situate themes within the broader population context. All sources are noted where applicable. 


\section{End notes}

1. Given the array of services available in each community, we purposely define "service delivery" broadly, encompassing both state and local systems that provide support in the form of cash assistance or vouchers (e.g., Temporary Assistance for Needy Families, subsidized housing), tangible goods (e.g., food pantries, clothing thrift stores, fuel assistance), training (e.g., workfare programs), and other resources (e.g., adult education, child advocacy, homelessness support, home weatherization). Service providers include formal employees of these agencies as well as volunteers contributing in a variety of capacities. To protect participant privacy, we do not disclose details about the service providers' specific professions.

2. Jennifer Sherman, "Rural Poverty: The Great Recession, Rising Unemployment, and the Under-Utilized Safety Net," in C. Bailey, L. Jensen, and E. Ransom, eds., Rural America in a Globalizing World: Problems and Prospects for the 2010s (Morgantown, WV: West Virginia University Press, 2014), pp. 523-42.

3. This challenge has also been identified in other rural New England places, whereby an overabundance of community development organizations contributes to a sense of inefficiency. See Michele Dillon, "Forging the Future: Community Leadership and Economic Change in Coös County, New Hampshire," Carsey Institute Report (Durham, NH: Carsey School of Public Policy, 2012).

4. Economic Policy Institute, "Ratio of Top 1\% Income to Bottom 99\% Income for All U.S. Counties, 2015," https://www.epi.org/chart/unequal-states-

2018-table-a1-individual-income-and-tax-data-forpennsylvania-by-size-of-adjusted-gross-income-taxyear-2015-2-2-2-2-2-2/.

\section{About the Authors}

Jess Carson is a research assistant professor at the Carsey School of Public Policy. Jess joined Carsey in May 2010 to study issues that affect vulnerable families and children. Much of her work at Carsey focuses on poverty, work, and the social safety net, including policies and programs that support low-income workers, such as food assistance programs, the minimum wage, and public health insurance.

Beth Mattingly is director of research on vulnerable families at the Carsey School of Public Policy. She manages all of Carsey's policy relevant work relating to family wellbeing. Topics covered by the vulnerable families research team range from refundable tax credits, Supplemental Nutrition Assistance Program (SNAP), and other federal programs, as well as policies that help families balance the domains of work and family such as access to affordable child care and paid sick leave. Her interests center on women, children, and family well-being. 


\section{A cknow ledgments}

The authors express deepest thanks to the participants in the Carsey Study on Community and Opportunity, who kindly shared their experiences and helped us understand their communities. The authors also thank Michael Ettlinger, Curt Grimm, Michele Dillon, Mil Duncan, and Anita Mathur at the Carsey School of Public Policy for feedback on earlier drafts of this brief, Laurel Lloyd and Bianca Nicolosi at the Carsey School for their assistance with layout, and Patrick Watson for editorial assistance. Additional thanks to attendees of the RUPRI Rural Poverty Conference, who provided valuable feedback on this work when it was presented as a poster in March 2018 and to the anonymous reviewers who provided feedback on the related journal article during the review process for Social Service Review.
This publication was made possible by Grant Number 90PD0275 from the Office of Planning, Research, and Evaluation, Administration for Children and Families, U.S. Department of Health and Human Services. Its contents are solely the responsibility of the authors and do not necessarily represent the official views of the Office of Planning, Research, and Evaluation, the Administration for Children and Families, or the U.S. Department of Health and Human Services.

\section{University of New Hampshire Carsey School of Public Policy}

The Carsey School of Public Policy at the University of New Hampshire is nationally recognized for its research, policy education, and engagement. The school takes on the pressing issues of the twenty-first century, striving for innovative, responsive, and equitable solutions.

Huddleston Hall • 73 Main Street • Durham, NH 03824

(603) 862-2821

TTY Users: DIAL 7-1-1 OR 1-800-735-2964 (RELAY N.H.)

carsey.unh.edu 